\title{
CARACTERIZAÇÃO MICROESTRUTURAL E ANÁLISES QUÍMICAS SEMI-QUANTITATIVAS DAS FASES FERRITA E AUSTENITA EM AÇOS INOXIDÁVEIS DUPLEX*
}

André de Albuquerque Vicente ${ }^{1}$ Débora Arruda Cabral ${ }^{2}$ Jorge Luís Coleti ${ }^{3}$ Victor Bridi Telles 4

Tiago Felipe de Abreu Santos ${ }^{5}$ Jorge Alberto Soares Tenório ${ }^{6}$

\begin{abstract}
Resumo
O valor do PREN da liga pode levar a uma previsão equivocada da resistência à corrosão por pite pois, caso haja um desbalanceamento das frações volumétricas da ferrita $\delta$ e da austenita, as composições químicas das fases poderão ser muito diferentes daquela da liga. Neste caso o PREN de uma das fases pode ficar abaixo do PREN da liga. Caracterizou-se três chapas de aços inoxidáveis duplex laminados com diferentes PRENs: UNS S32304 (Lean Duplex), UNS S31803 (Duplex) e UNS S32750 (Super Duplex). Várias técnicas complementares de análise microestrutural foram utilizadas, tais como de espectrometria de emissão ótica, microscopia óptica e microscopia eletrônica de varredura com EDS acoplado. Realizaram-se análises metalográficas quantitativas para a determinação das frações volumétricas de ferrita $\delta$ e da austenita e análises químicas semi-quantitativas das fases presentes utilizando-se um MEV com EDS acoplado.

Palavras-chave: Aços Inoxidáveis Duplex; PREN; Frações Volumétricas.

\section{MICRO-STRUCTURAL CHARACTERIZATION AND SEMI-QUANTITATIVE CHEMICAL ANALYSIS OF FERRITE AND AUSTENITE PHASES IN DUPLEX STAINLESS STEELS}

\section{Abstract}

The PREN value of the alloy may lead to a misleading prediction of pitting corrosion resistance because in the event of an imbalance of $\delta$ ferrite and austenite volume fraction, the chemical composition of the phases may be very different from that of the alloy. In this case, the PREN of one of the phases may be below the PREN of the alloy. Three laminated duplex stainless steels with different PRENs were characterized: UNS S32304 (Lean Duplex), UNS S31803 (Duplex) and UNS S32750 (Super Duplex). Several complementary techniques of microstructural analysis were used, such as optical emission spectrometry, optical microscopy and scanning electron microscopy with coupled EDS. Quantitative metallographic analyzes were carried out to determine the volume fraction of $\delta$ ferrite and austenite and semiquantitative chemical analyzes of the present phases using a coupled EDS-SEM.

Keywords: Duplex Stainless Steels; PREN; Volume Fraction.

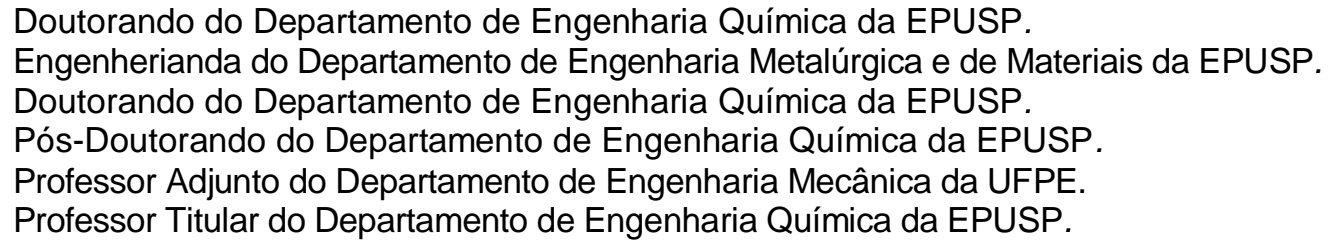

Doutorando do Departamento de Engenharia Química da EPUSP.

Engenherianda do Departamento de Engenharia Metalúrgica e de Materiais da EPUSP.

Doutorando do Departamento de Engenharia Química da EPUSP.

Pós-Doutorando do Departamento de Engenharia Química da EPUSP.

Professor Adjunto do Departamento de Engenharia Mecânica da UFPE.

Professor Titular do Departamento de Engenharia Química da EPUSP. 


\section{INTRODUÇÃO}

Os aços inoxidáveis dúplex (AID) são aços que apresentam microestrutura bifásica contendo ferrita e austenita em frações volumétricas aproximadamente iguais a $50 \%$ [1]. Em razão da sua microestrutura bifásica esses aços apresentam uma combinação favorável das propriedades dos aços inoxidáveis ferríticos e austenítcos, ou seja, apresentam elevada resistência mecânica, boa tenacidade e ductilidade além de boa resistência à corrosão em diversos meios [1]. Esta combinação favorável de propriedades faz esta classe de aços inoxidáveis ser amplamente empregada em indústrias petroquímica, papel e celulose e, mais recentemente, em hidro geração [1]. Os aços dúplex são baseados no diagrama de fases ternário Fe-Cr-Ni apresentado na figura 1.

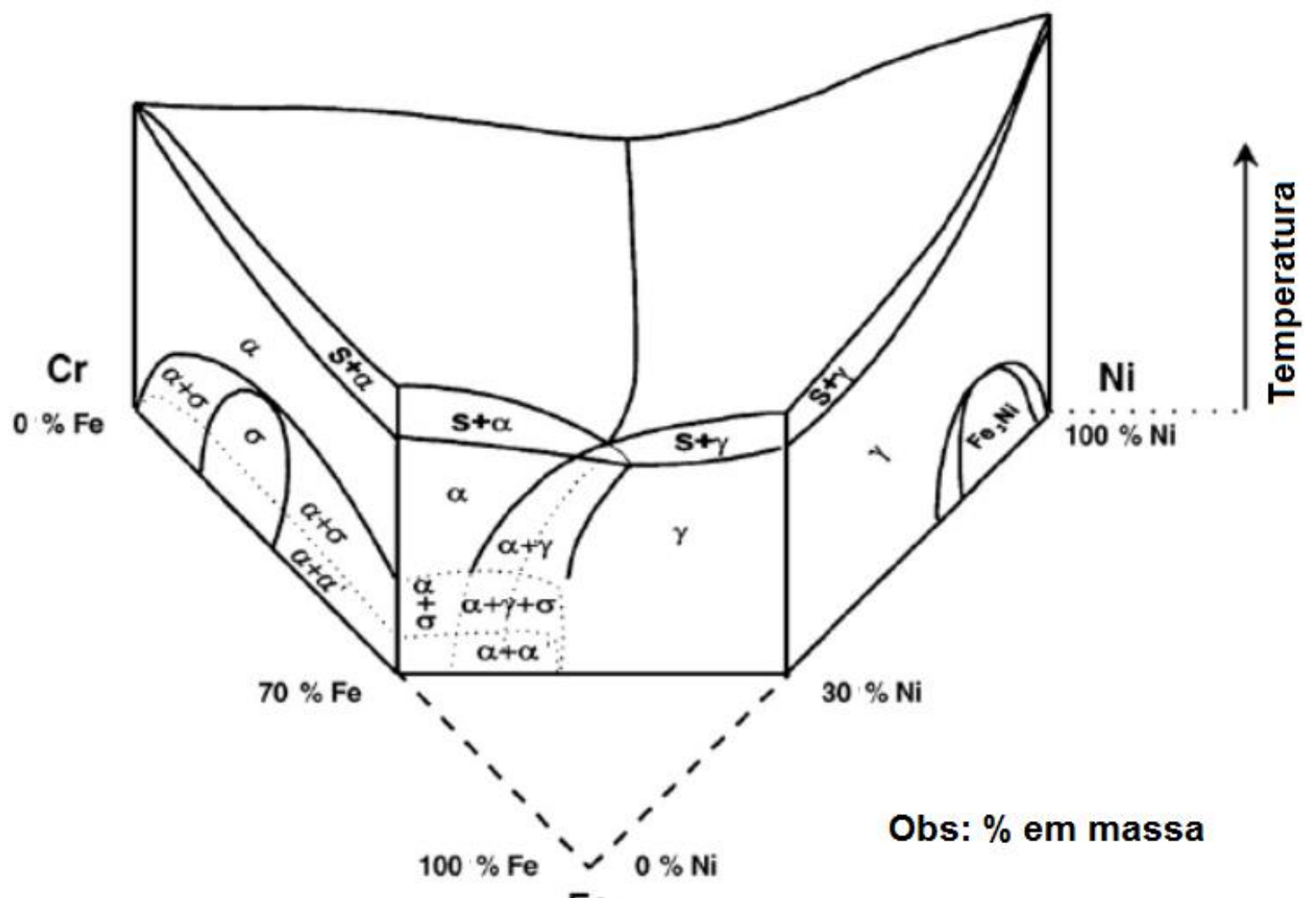

Figura 1 - Diagrama de fases ternário Fe-Cr-Ni destacando-se o diagrama pseudo-binário Cr-Ni para $70 \%$ de Fe. [1].

Os aços inoxidáveis dúplex solidificam conforme solidificação ferrítica-austenítica $(\mathrm{L} \rightarrow \mathrm{L}+\delta \rightarrow \mathrm{L}+\delta+\gamma \rightarrow \delta+\gamma)$. A ferrita $\delta$ solidifica como fase primária de modo dendrítico ou celular. Com a diminuição da temperatura, forma-se austenita por meio de uma reação peritética $(L+\delta \rightarrow \gamma)$ ou eutética $(L \rightarrow \delta+\gamma)$. No caso de reação peritética, a austenita formada inicialmente circunda completamente a ferrita e cresce subseqüentemente, para a ferrita e para o líquido. Dependendo da velocidade de difusão através da austenita, a reação pode se completar ou não, e ao final da solidificação poderá restar ferrita envolvida por austenita. Entre as duas reações peritética e eutética - ocorre a transição onde, durante a formação inicial de austenita por reação peritética, elementos ferritizantes segregam para o líquido, provocando o seu enriquecimento nestes elementos e consequentemente a formação simultânea de ferrita e austenita por meio de uma reação eutética [2]. 
Uma maneira de se quantificar empiricamente a resistência à corrosão por pite, é através da fórmula PREN (Pitting Resistance Equivalent Number), ou PRENN (equação 1) e PRENw (equação 2), quando tratamos de materiais que possuem Tungstênio (W) em sua composição, segundo Gunn [3].

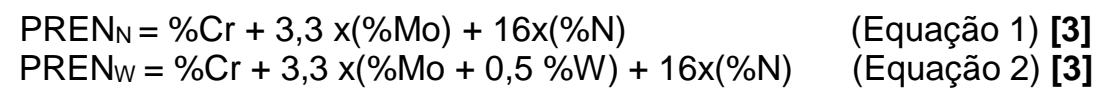

(Equação 1) [3]

(Equação 2) [3]

Os principais elementos de liga, além do ferro, presentes nas composições químicas dos aços inoxidáveis duplex são:

- Cromo (Cr): é o elemento responsável pela formação da camada passiva, principal formador de óxido da camada protetora, sua concentração em peso nos duplex é de no mínimo $22 \%$. O Cr estabiliza a estrutura cúbica de corpo centrado, ele é estabilizador da ferrita. Deve-se controlar a concentração deste elemento de liga, pois, em altas concentrações, ele promove a formação de compostos intermetálicos [4]. Quanto maior for o teor de Cr maior deverá ser o teor de $\mathrm{Ni}$ (formador de austenita) a fim de garantir um balanceamento entre as fases austenita e ferrita.

- Molibdênio (Mo): Aumenta a passividade e a resistência química dos aços inoxidáveis. Sua ação é especialmente importante no aumento da resistência à corrosão por pite e por frestas, atua conjuntamente com o $\mathrm{Cr}$ para formar a fase ferritica. Em altas concentrações, assim como o $\mathrm{Cr}$, contribui para geração de compostos intermetálicos prejudiciais [4].

- Níquel (Ni): é um forte austenitizante, conferindo maior ductilidade, resistência mecânica e soldabilidade além de atrasar a formação de fases intermetálicas, tornando o aço não magnético. Associado ao Cromo favorece o aumento da resistência à corrosão [4]. O excesso de Ni pode levar ao desbalanceamento entre as fases ferrita e austenita. O percentual de austenita pode superar demasiadamente os $50 \%$. A conseqüência disso é que a ferrita restante apresentará uma concentração excessiva de $\mathrm{Cr}$ e Mo, com isso haverá o risco da ferrita transformar-se facilmente em uma fase intermetálica quando exposta a uma temperatura entre 650 e $900^{\circ} \mathrm{C}$.

- Nitrogênio (N): é um forte formador de austenita. O nitrogênio garante a elevada resistência mecânica. Este elemento retarda a precipitação de carbonetos de cromo em temperaturas de tratamento entre 650 e $900^{\circ} \mathrm{C}$, devido à formação preferencial de nitretos, evitando assim um empobrecimento acentuado de cromo em regiões intergranulares nessas condições [5]. É usado também para reduzir o preço do material uma vez que ao adicionar-se este elemento pode-se reduzir significativamente a adição de Ni. Pode ser adicionado também durante o processo de soldagem através do gás de proteção e/ou purga.

- Manganês (Mn): Sua principal função é de anular o efeito de impurezas nos aços, como o oxigênio e o enxofre. Pequenas quantidades deste elemento, associadas à presença de níquel, melhora substancialmente a resistência mecânica, entretanto, diminui a ductilidade.

- Cobre (Cu): Apresenta boa condutividade térmica, elétrica e boa usinabilidade. Sua presença aumenta a resistência à corrosão por via úmida; entretanto, provoca aumento na cinética de precipitação da fase sigma.

- Tungstênio (W): A adição de Tungstênio em teores de até $2 \%$ melhora a resistência à corrosão por pite e por frestas principalmente em ambientes 
clorídricos devido à colaboração do W na estabilização da camada passiva de óxidos. $\mathrm{O}$ W favorece a formação de fases intermetálicas entre 700 e $1000^{\circ} \mathrm{C}$ bem como a formação de austenita secundária na poça de fusão no caso de juntas soldadas [3].

- Carbono (C): causa endurecimento e aumento na resistência mecânica da liga. Associado ao cromo prejudica a resistência à corrosão.

A figura 2 apresenta uma curva PTT típica de um aço inoxidável super duplex destacando o efeito dos principais elementos de liga na precipitação de fases deletérias.

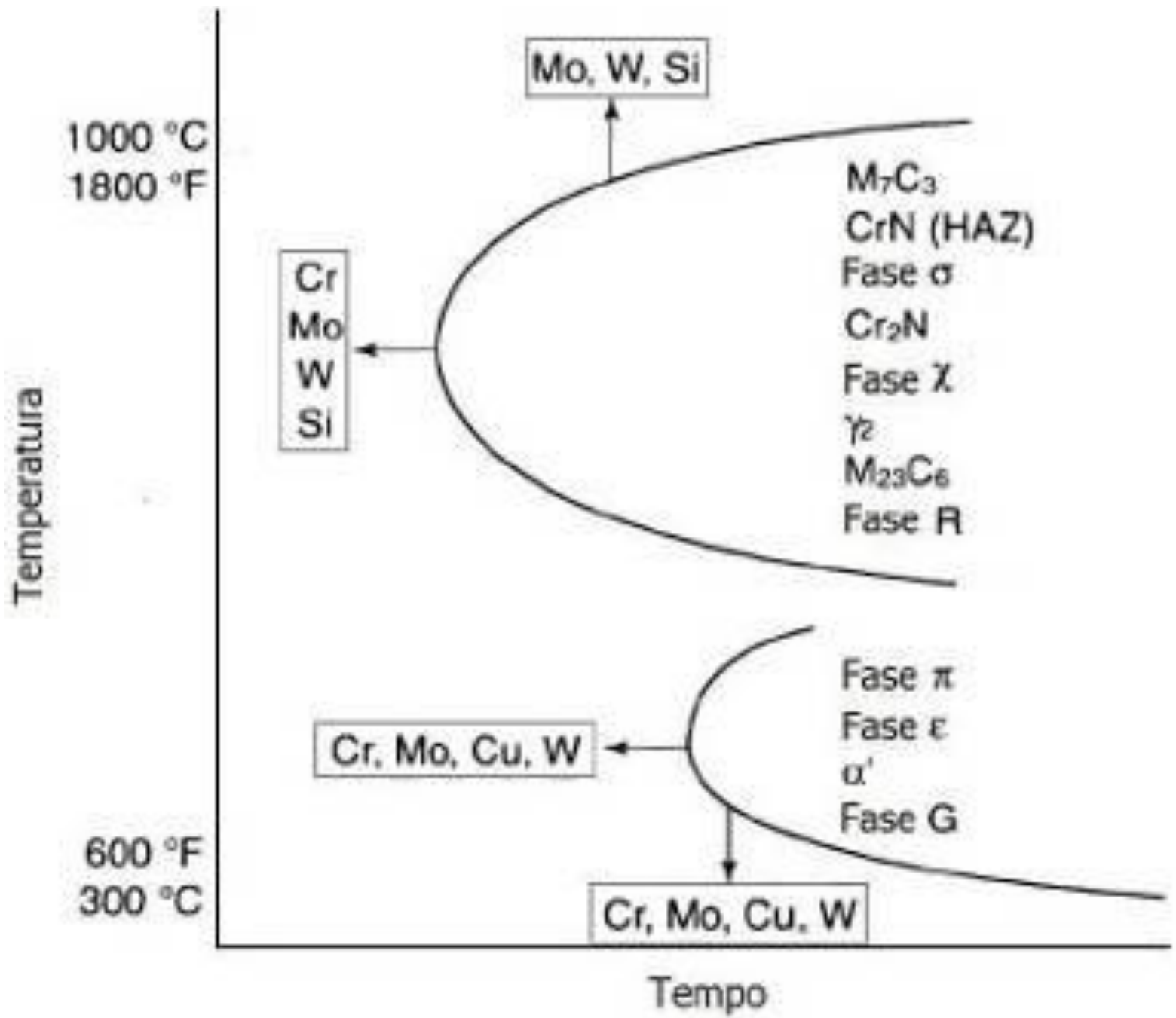

Figura 2 - Curva PTT típica de um aço super duplex destacando o efeito de alguns elementos de liga na precipitação de fases deletérias [3].

O cálculo do PREN da liga será importante para previsão da resistência à corrosão por pite da mesma. No caso dos aços duplex, o valor do PREN da liga pode levar a uma previsão equivocada de resistência à corrosão por pite pois, caso haja um desbalanceamento das frações volumétricas da ferrita $\delta$ e da austenita, as composições químicas da ferrita $\delta$ e da austenita poderão ser muito diferentes daquela da liga. Neste caso o PREN de uma das fases, ferrita $\delta$ ou austenita, pode ficar abaixo do PREN da liga. A ausência de fases deletérias é também de fundamental importância. Faz sentido, então, medirem-se as composições químicas 
das fases ferrita e austenita e, posteriormente, calcular seus PRENs e compará-los com o PREN da liga. O PREN verdadeiro será o menor PREN encontrado.

\section{MATERIAIS E MÉTODOS}

Utilizaram-se três chapas de aços inoxidáveis duplex laminados, com espessura de 16,00mm. Os aços inoxidáveis duplex utilizados são o UNS S32304 (Lean Duplex), UNS S31803 (Duplex) e UNS S32750 (Super Duplex). Realizaram-se análises químicas em todos os corpos de através de espectrômetro de emissão ótica, conforme a norma ASTM E 1086-08 [6]. Cortaram-se os corpos de prova das chapas utilizando-se um cut-off com disco para aços inoxidáveis. Posteriormente as amostras foram embutidas em resina termofixa de cura à quente (baquelite). Empregou-se o polimento manual convencional utilizando-se lixas d'água $(100,240$, 320, 400, 600 e 1000 mesh) com o objetivo de se padronizar o acabamento superficial das amostras. Posteriormente realizou-se o polimento em pano com pasta abrasiva de diamante, de 9, 3 e $1 \mu \mathrm{m}$, nessa sequência. As amostras foram atacadas eletroliticamente em solução de $\mathrm{NaOH} 20 \%, 6 \mathrm{~V}$, por 90 segundos. Isto permitiu a caracterização microestrutural das amostras através de microscopia óptica, bem como uma melhor observação no MEV das fases presentes. As análises metalográficas quantitativas para a determinação das frações volumétricas de ferrita e austenita foram realizadas conforme a norma ASTM E 562 ed. 08 [7] utilizando-se uma grade de $4 \times 5$ (20 pontos) com aumento de 400X em 30 regiões distintas por corpo de prova. Realizaram-se análises químicas semi-quantitativas das fases presentes utilizando-se um MEV com EDS acoplado.

\section{RESULTADOS E DISCUSSÃO}

A tabela 1 apresenta as composições químicas bem como os PRENs dos aços inoxidáveis estudados.

Tabela 1 - Composições químicas dos aços inoxidáveis estudados (\% em peso).

\begin{tabular}{c|c|c|c|c|c|c|c|c|c|c|c}
\hline Especificação & $\% \mathrm{C}$ & $\% \mathrm{Si}$ & $\% \mathrm{Mn}$ & $\% \mathrm{P}$ & $\% \mathrm{~S}$ & $\% \mathrm{Cr}$ & $\% \mathrm{Ni}$ & $\% \mathrm{Mo}$ & $\% \mathrm{Cu}$ & $\% \mathrm{~N}$ & PREN \\
\hline $\begin{array}{c}\text { UNS S32304 } \\
\text { (Lean Duplex) }\end{array}$ & 0,018 & 0,38 & 1,41 & 0,025 & 0,002 & 23,39 & 4,84 & 0,19 & 0,32 & 0,12 & 25,94 \\
\hline $\begin{array}{c}\text { UNS S31803 } \\
\text { (Duplex) }\end{array}$ & 0,015 & 0,43 & 1,51 & 0,023 & 0,001 & 22,61 & 5,80 & 3,13 & 0,12 & 0,17 & 35,66 \\
\hline $\begin{array}{c}\text { UNS S32750 } \\
\text { (Super Duplex) }\end{array}$ & 0,013 & 0,43 & 0,64 & 0,024 & 0,000 & 24,91 & 6,97 & 3,76 & 0,08 & 0,28 & 41,80 \\
\hline
\end{tabular}

A figura 3 apresenta as micrografias dos aços inoxidáveis duplex estudados. Observam-se as microestruturas típicas de aços inoxidáveis duplex laminados, onde a fase escura é ferrita $\delta$ e a fase clara austenita. 

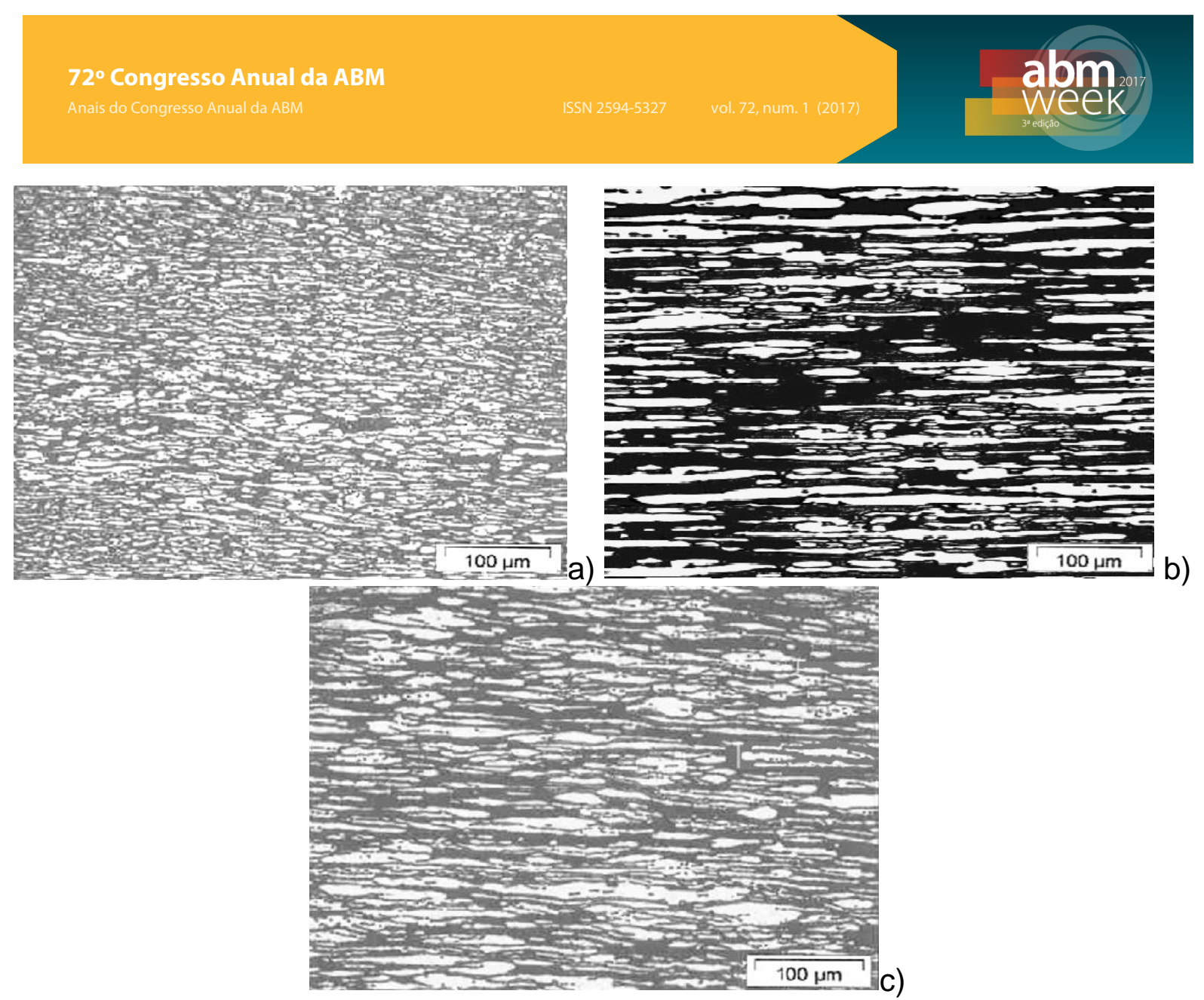

Figura 3 - Micrografias dos aços inoxidáveis: a) Lean Duplex UNS S 32304, b) UNS S31803 (Duplex) e c) UNS S32750 (Super Duplex).

A tabela 2 apresenta as frações volumétricas de ferrita $\delta$ e de austenita obtidas através de medições em 30 regiões distintas por corpo de prova.

Tabela 2 - Frações volumétricas de ferrita e austenita

\begin{tabular}{c|c|c|c}
\hline Especificação & $\% \mathbf{8}$ & $\mathbf{9 5 \%} \mathbf{~ I ~}$ & $\% \mathbf{R A}$ \\
\hline UNS S32304 (Lean Duplex) & 50,17 & 4,32 & 8,61 \\
\hline UNS S31803 (Duplex) & 52,48 & 3,26 & 6,21 \\
\hline UNS S32750 (Super Duplex) & 51,97 & 3,98 & 7,66 \\
\hline
\end{tabular}

Analisando-se os dados da Tabela 2, verifica-se que as frações volumétricas médias de ferrita $\delta$ e da austenita estão próximas de 50\% cada. Desta forma é razoável prever que haja uma partição de soluto ideal entre as duas fases, sendo que a ferrita $\delta$ deverá apresentar teores maiores dos elementos de liga ferritizantes cromo e o molibdênio. Da mesma forma, a austenita deverá apresentar teores maiores dos elementos de liga austenitizantes níquel e nitrogênio. Nesta condição ideal de frações volumétricas de ferrita $\delta$ e austenita é razoável esperar PRENs próximos ao PREN da liga. A figura 4 apresenta as análises metalográficas e as respectivas caracterizações das fases dos aços inoxidáveis Lean Duplex, Duplex e Super Duplex bem como os respectivos espectros de EDS que permitiram as análises químicas semi-quantitativas da ferrita e da austenita através de MEV com EDS acoplado. 

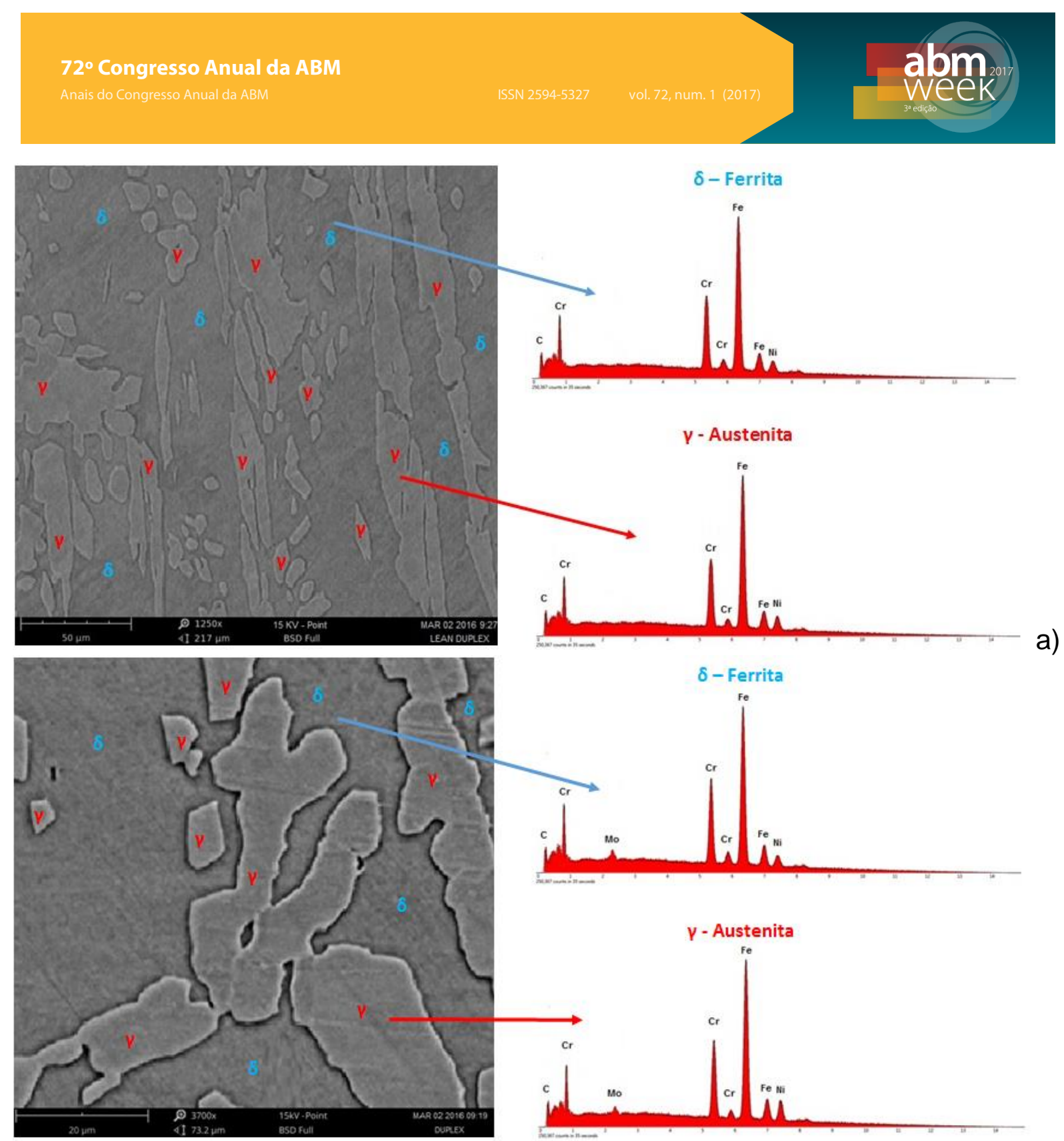

b)

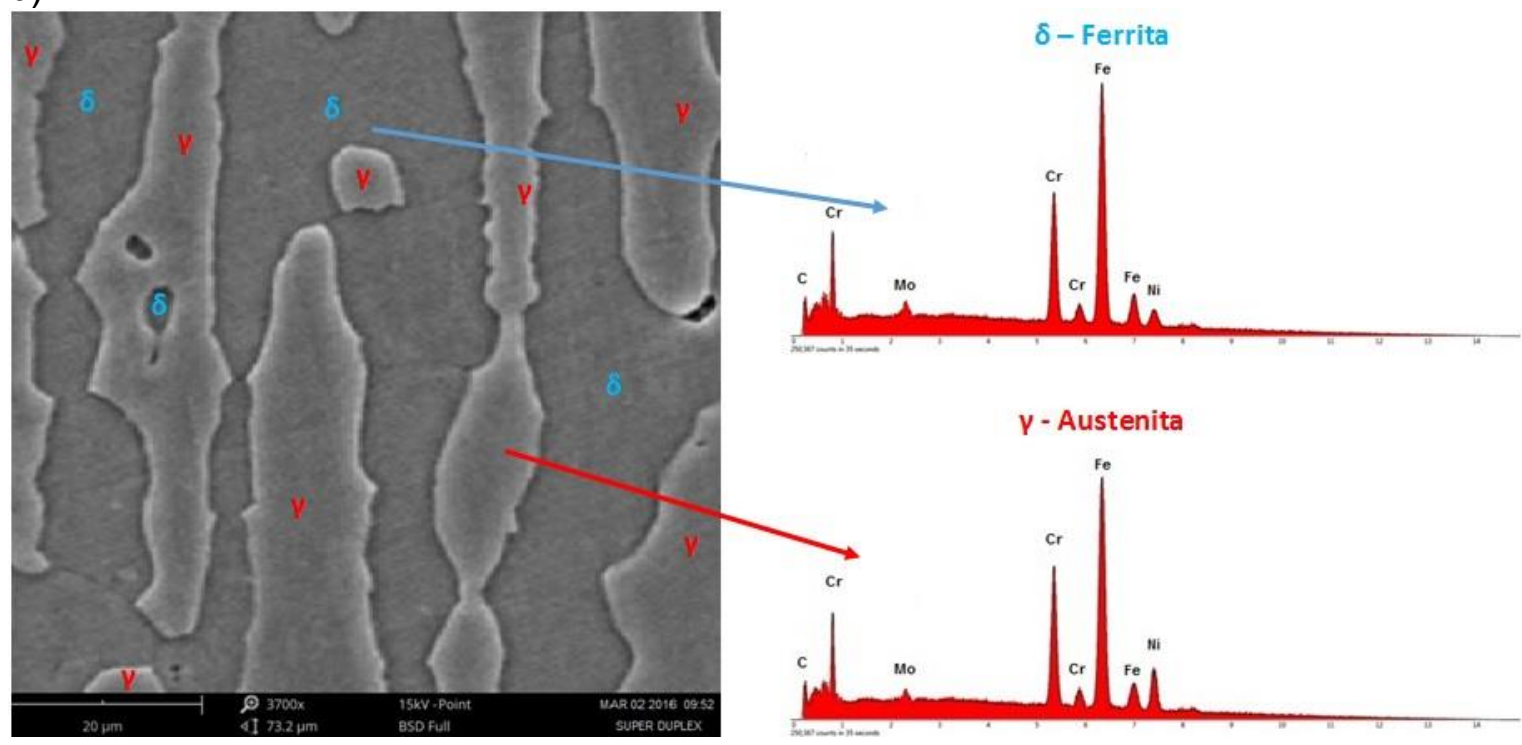

c)

Figura 4 - Análises metalográficas e as respectivas caracterizações das fases dos aços inoxidáveis a) Lean Duplex, b) Duplex e c) Super Duplex bem como os respectivos espectros de EDS. 
Observa-se na Figura 4 a ausência de picos bem definidos do elemento de liga molibdênio nos espectros de EDS das fases ferrita $\delta$ e austenita do aço inoxidável Lean Duplex. Tal observação é coerente com os valores apresentados na Tabela 1, onde o teor médio do elemento de liga molibdênio é de apenas 0,19\% em peso. Analisando-se os espectros de EDSs mostrados na figura 4, observa-se a fase ferrita $\delta$ apresenta teores de $\mathrm{Cr}$ e Mo mais altos que a fase austenita. Por outro lado a austenita apresenta teores de $\mathrm{Ni}$ mais altos que a ferrita $\delta$. A técnica não permitiu medir o teor de $\mathrm{N}$ das fases. No diagrama de fases $\mathrm{Fe}-\mathrm{N}$ verifica-se que o limite de solubilidade de nitrogênio na ferrita é $0,10 \%$ em peso a $592{ }^{\circ} \mathrm{C}$ e que o limite de solubilidade de nitrogênio na austenita é $2,8 \%$ em peso a $650{ }^{\circ} \mathrm{C}$. Os aços inoxidáveis duplex são ligas n-árias e, portanto, a utilização de um diagrama binário $\mathrm{Fe}-\mathrm{N}$ pode parecer muito simplista. Entretanto, devido à dificuldade de medir-se o teor de nitrogênio nas fases, tomou-se o diagrama Fe-N apresentado na figura 5 como uma referência. Desta forma considerou-se razoável considerar que o teor máximo de nitrogênio na ferrita seja exatamente o limite de solubilidade deste elemento na ferrita, ou seja, $0,10 \%$. Desta forma para o cálculo médio dos PRENs das fases, arbitrou-se o teor de nitrogênio na ferrita como $0,09 \%$ em peso para todos os aços inoxidáveis estudados.

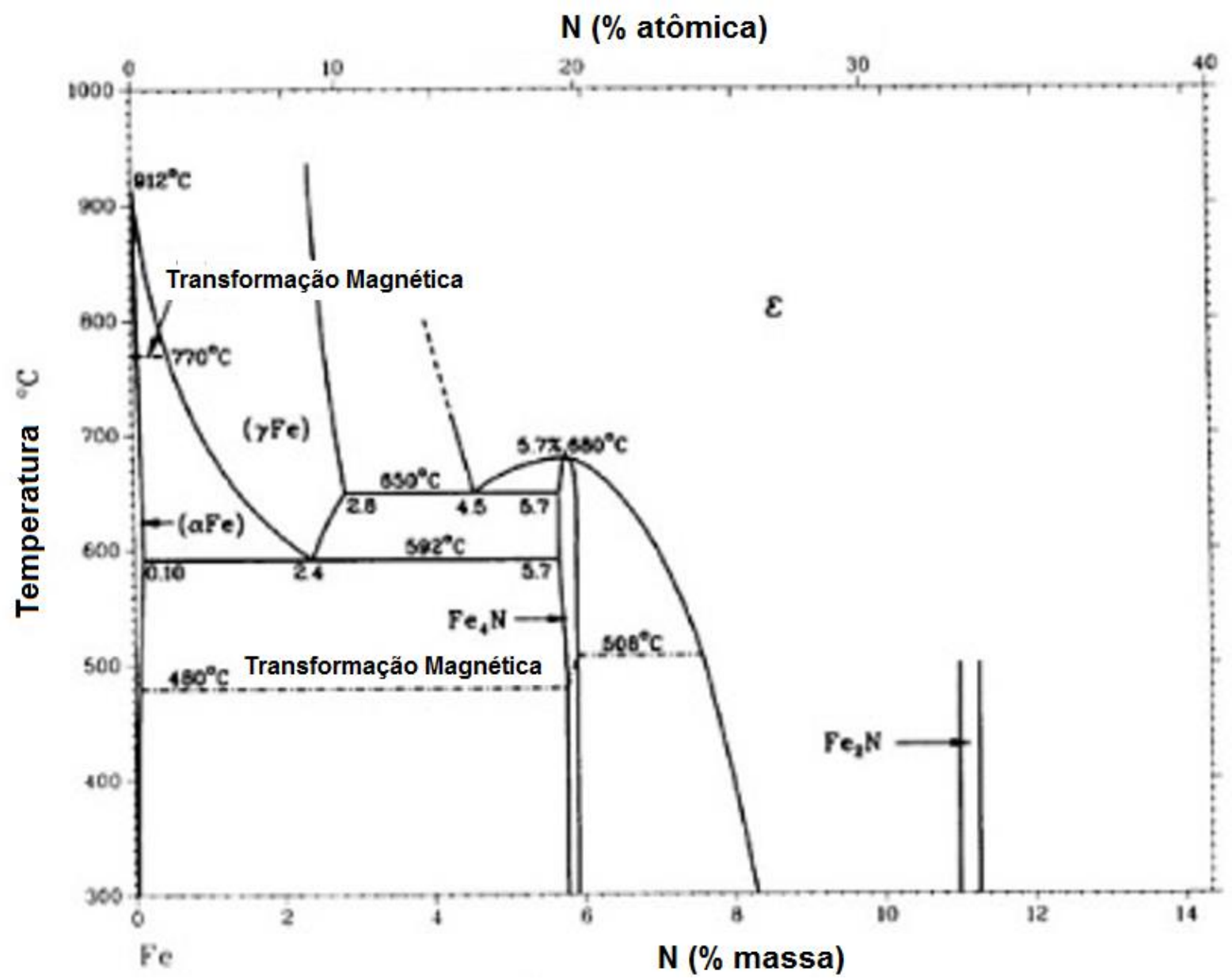

Figura 5 - Diagrama de fases Fe-N [8].

A partir das análises químicas das ligas apresentadas na Tabela 1 e das análises químicas semi-quantitativas obtidas através de microscopia eletrônica de varredura com EDS acoplado para as fases ferrita e austenita, calculou-se os PRENs 
utilizando-se a fórmula apresentada na equação 1. A Tabela 3 apresenta as composições químicas médias das ligas e das fases ferrita $\delta$ e austenita.

A tabela 3 apresenta os resultados de PRENs calculados para os três aços inoxidáveis estudados e para as fases ferrita e austenita, respectivamente.

Os erros percentuais na medição da composição química das fases ferrita e austenita por EDS do $\mathrm{Cr}$ e do Mo são de $2 \%$. Os teores de $\mathrm{N}$ nas fases foram calculados a partir do teor médio de $\mathrm{N}$ das ligas considerando-se que o \% $\mathrm{N}$ na ferrita seja $0,09 \%$.

Tabela 3 - Composições químicas das ligas e das fases ferrita e austenita, frações volumétricas e cálculos de PRENs.

\begin{tabular}{c|c|c|c|c|c}
\hline & $\mathbf{C r}$ & Mo & $\mathbf{N}$ & PREN & Frações Volumétrica (\%) \\
\hline Lean Duplex & $\mathbf{2 3 , 3 9}$ & $\mathbf{0 , 1 9}$ & $\mathbf{0 , 1 2}$ & $\mathbf{2 5 , 9 4}$ & \\
\hline Ferrita & 24,23 & 0,20 & 0,09 & 26,33 & $\mathbf{5 0 , 1 7}$ \\
\hline Austenita & 21,87 & 0,18 & 0,15 & 24,86 & $\mathbf{4 9 , 8 3}$ \\
\hline Duplex & $\mathbf{2 2 , 6 1}$ & $\mathbf{3 , 1 3}$ & $\mathbf{0 , 1 7}$ & $\mathbf{3 5 , 6 6}$ & \\
\hline Ferrita & 23,92 & 3,11 & 0,09 & 35,62 & $\mathbf{5 2 , 4 8}$ \\
\hline Austenita & 20,44 & 3,08 & 0,25 & 34,61 & $\mathbf{4 7 , 5 2}$ \\
\hline Super Duplex & $\mathbf{2 4 , 9 1}$ & $\mathbf{3 , 7 6}$ & $\mathbf{0 , 2 8}$ & $\mathbf{4 1 , 8 0}$ & \\
\hline Ferrita & 25,84 & 3,88 & 0,09 & 40,08 & $\mathbf{5 1 , 9 7}$ \\
\hline Austenita & 23,13 & 3,57 & 0,47 & 42,44 & $\mathbf{4 8 , 0 3}$
\end{tabular}

Observa-se na Tabela 3 que a fase ferrita $\delta$ apresentou teores de cromo e de molibdênio superiores aos da fase austenita.

Conforme esperado existem importantes diferenças entre as composições químicas das fases ferrita $\delta$ e austenita resultando em PRENs diferentes àqueles da composições das ligas.

\section{CONCLUSÃO}

No caso dos aços duplex, o valor do PREN da liga pode levar a uma previsão de resistência à corrosão por pite equivocada pois, caso haja um desbalanceamento das frações volumétricas da ferrita $\delta$ e da austenita, as composições químicas da ferrita $\delta$ e da austenita serão diferentes àquela da liga.

Para todos os aços inoxidáveis duplex estudados, observou-se que a fase ferrita $\delta$ apresenta teores de $\mathrm{Cr}$ e Mo mais altos que a fase austenita. Por outro lado a austenita apresenta teores de Ni mais altos que a ferrita $\delta$.

Para todos aços inoxidáveis duplex estudados, o PREN de uma das fases, ferrita $\delta$ ou austenita, ficou abaixo do PREN da liga.

\section{Agradecimentos}

À SMT - Sandvik Materials Technology, representada pelo caro colega politécnico Fausto Camargo e pelo caro amigo Luiz Gobbis, por acreditar neste projeto e pela doação do metal base e do consumível de soldagem bem como por sempre apoiar a Escola Politécnica da Universidade de São Paulo quando existe o interesse em realizar-se estudos envolvendo ligas resistentes à corrosão. 
À Prax Air representada pelos caros colegas Marcos Lobato e Jeferson Costa, por acreditar neste projeto e pela doação dos gases de proteção para a soldagem e do ar sintético para os ensaios de oxidação bem como por sempre apoiar a Escola Politécnica da Universidade de São Paulo quando existe o interesse em realizar-se estudos envolvendo gases especiais.

\section{REFERÊNCIAS}

1) DA SILVA, ALINE. Efeito da Temperatura de Solubilização na Precipitação de Fase Sigma de um Aço Inoxidável Superdúplex. Dissertação de mestrado, Universidade Federal de Itajubá, Itajubá, 2011.

2) GAZIRE, R.C.. Efeito da Velocidade de Resfriamento na Microestrutura de solidificação de Aço Inoxidável Austenítico Tipo AISI 316L com Adições de Boro. Dissertação de Mestrado. Escola Politécnica da USP, Departamento de Engenharia Metalúrgica, São Paulo, 1993.

3) GUNN, R. N.; Duplex Stainless Steels: Microstructure, properties and applications. Cambridge: Abington Publishing, 1997, 204p.

4) SEDRIKS, A. J.; Corrosion of Stainless Steels (2nd edition), 1996, $437 \mathrm{p}$.

5) PARK, Y. H.; LEE, Z. H.; The Effect of Nitrogen and Heat Treatment on the Microstructure and Tensile Properties of $25 \mathrm{Cr}-7 \mathrm{Ni}-1.5 \mathrm{Mo}-3 \mathrm{~W}-\mathrm{xN}$. Duplex Stainless Steel Casting. Materials Science and Engineering A297, 2001.

6) ASTM E1086-08: Standard Test Method for Optical Emission Vacuum Spectrometric Analysis of Stainless Steel by the Point-to-Plane Excitation Technique, ASTM International, West Conshohocken, PA, EUA, 2008.

7) ASTM E562-08: Standard Test Method for Determining Volume Fraction by Systematic Manual Point Count, ASTM International, West Conshohocken, PA, EUA, 2008.

8) ASM Handbook. Volume 3, Alloy phase diagrams. ASM International. Handbook Commitee, Materials Park, Ohio: ASM International, 1992. 